\title{
The Significance of Being Ethical: An essay on the case for moral realism and theism*
}

\author{
CHARLES TALIAFERRO \\ St. Olaf College, Northfield, Minnesota, United States \\ taliafer@stolaf.edu
}

\begin{abstract}
William Irwin defends a form of moral anti-realism, according to which there are no objective moral facts. He contends that moral realism is objectionable because of its being more complex or not as simple as anti-realism; moral realism is in conflict with science; moral realism is also challenged by the fact that our moral judgements would differ if we were subject to a different biology or evolutionary past. Irwin also argues that insofar as moral realism is supportable evidentially by experience this would lead to the absurdity of thinking theism may be supported evidentially by religious experience. In response, it is argued that there are many truths (about logic and mathematics) and practices (such as science itself) that are not intelligible if there are no objective, normative truths and that objective moral truths are no more dispensable or odd than epistemic norms. It is further argued that Irwin's account of the evolution of morality is not able to escape presupposing objective moral facts (about harm and benefaction). Finally, the appeal to moral and religious experience is defended in making the case for moral realism and theism.
\end{abstract}

Keywords: moral realism; moral anti-realism; objective moral facts; theism; William Irwin; Michael Ruse; E.O. Wilson.

I am grateful to two anonymous referees of this journal for helpful suggestions on an earlier draft of this essay. 
In The Free Market Existentialist, William Irwin defends a form of moral anti-realism, according to which ethical judgments of right and wrong, good and bad are neither true nor false. They have an apparent objective reality, but this turns out to be illusory. Irwin's case for claiming that all our judgements about acts being morally right or wrong are based on a mistaken assumption of objectivity (such a claim is sometimes called error theory) and Irwin's reasons for adopting it, are not completely unique, but some of his claims about the illusory nature of objective morality are interesting for his linking them to claims about the illusory nature of theism. His position is also developed systematically and with a clarity that invites engagement. There are three sections that follow. The first is an exposition of Irwin's position. The second replies to Irwin's arguments and offers a defence of moral realism. The third offers some observations comparing a case for moral realism and theism.

\section{Moral Anti-Realism}

Irwin joins Michael Ruse and E.O. Wilson in their claiming that evolutionary biology gives us reason for thinking that our moral judgements are not objectively right or wrong, true or false. Famously, Michael Ruse observes that "morality is a collective illusion foisted upon us by our genes" (Ruse 1986, 253). Ruse and Wilson write: "The evolutionary explanation makes the objective morality redundant, for even if external ethical premises did not exist, we would go on thinking about right and wrong in the way that we do" (Ruse and Wilson 1994, 431). There are at least three reasons why Irwin shares with Ruse and Wilson a form of moral anti-realism: First, it is a more simple or parsimonious explanation of our ethical judgments and feelings than moral realism. We can fully account for our ethical judgments without positing objectively true moral facts. Related to this reason is the second charge that moral realism involves positing something (perhaps nonphysical) that goes beyond the parameter of science. Third, while moral realism is not subject to disproof, there is no evidence (or there is insufficient evidence) for the truth of moral realism. There is a fourth reason 
that I will note below but not systematically engage. The rejection of moral realism paves the way for his atheistic, existentialism which form the foundation for his political libertarianism, his advocacy of small government compatible with giving individuals a very large fee site for economic and other social exchanges.

On accounting for our moral judgments, Irwin writes that all that is necessary is evolutionary biology.

Humans evolved to live together in groups of approximately 35-150. In order to survive and pass on their genes, individuals had to adapt to group norms, the most basic of which is reciprocity, helping those who help you and harming those who harm you. (Irwin 2015, 94)

A form of moral realism according to which our moral judgements track objective properties or feature of the world is comparatively odd.

Now we have a perfectly good explanation of why we form moral judgments that does not call for any of the odd abilities or properties that those attempts to hold on to moral realism require... The tracking explanation is scientifically unacceptable. Contra tracking accounts, our evaluative tendencies evolved not because they tracked moral facts but because they led to us surviving and reproducing. This explanation is more parsimonious, clearer, and sheds more light on what is to be explained: widespread tendencies to make certain kind of evaluative judgments. (Irwin 2015, 105; emphasis mine)

Take special note that Irwin holds that moral realism (that claims our ethical judgements track objective moral relations) is "scientifically unacceptable." Although Irwin does not explicitly object to moral realism because he believes it is committed to there being non-physical phenomena, this is strongly suggested when he places "moral facts" on the same evidential level as belief that there are supernatural entities. "Given the evidence of modern science," writes Irwin, "most people are error theorists about ghosts; others too are error theorists about angels, souls, and gods... Likewise, we can conclude without proof of their existence, moral facts do not exist.” (Irwin 2015, 101) 
While we do have strong intuitions and experiences of the objectivity of ethics, this is a matter of mere feeling and not evidence.

Advocates of objective morality often fall back on a piece of subjective evidence: morality feels true. That may be, but we need to ask why. Does morality feel true because we were raised with morality? ... The fact that a thing feels true may provide subjective reason to look for an objective reason that validates the subjective feeling, but if no such reason is forthcoming, the feeling must be rejected as insufficient evidence. (Irwin 2015, 105-106)

Irwin notes the pervasiveness of our ethical feelings:

It certainly is true that, aside from psychopaths, virtually all human being will find the torture of children for fun to be abhorrent. But that feeling does not make it true that the action is morally wrong. (Irwin 2015, 101-102)

But does it provide evidence that it is morally wrong? No.

The feeling is not proof of an objective moral fact; it is simply evidence for an evolved reaction of strong disapproval. As strange and awful as it sounds, if our evolutionary history had been different we could have developed the tendency to approve of the torture of children. The near universal reaction of moral disapproval establishes nothing about objective morality. (Irwin 2015, 103)

Irwin likens our response to events in ethical terms to the biological reaction to dog faeces.

The fact that nearly every human being with normal olfactory operation finds the smell of dog droppings to be disgusting does not mean that dog droppings objectively smell disgusting. Rather, what the evidence tells us is that, given the senses human have evolved, dog droppings smell bad to nearly all humans. Does that mean they smell bad objectively? Not in any objectively real or supernatural sense. Consider the fact that dogs seem to love the smell of dog droppings. With just some small difference in our evolutionary history, we might have come to really enjoy the smell of dog droppings too. (Irwin 2015, 103) 
Irwin considers one possible way in which the feelings that we have that morality is objective might find an evidential footing, namely if we appeal to epistemological conservatism, according to which we should treat as justified longstanding beliefs. But this move seems to Irwin to be unwarranted.

The intuition is strong that morality, good and bad, right and wrong are objectively real properties of the world, and epistemological conservatism would favour maintaining that intuition / belief unless the burden of proof otherwise can be met. However, we should reject this epistemological conservatism. There are any number of beliefs that are naturally very strong and that turn out to be false: the earth is flat, the sun orbits the earth, and so forth. When it comes to an existence belief, or existential claim, the burden of proof should, all other things being equal, be on the person making the existential claim. So when someone claims that non-physical entities or properties such as good and evil exist, the burden should be on them to prove it. (Irwin 2015, 106)

Irwin concedes that giving up on the conviction that morality is objectively true can lessen one's motive to do what one might otherwise believe is right. "Admittedly, it is harder to motivate oneself to take certain actions once one gives up belief in objective morality." (Irwin 2015,113) But in the end, he advances an ethic of enlightened self-interest which he believes will provide all we need in terms of constructing a sound basis for a social-political-economic community. This is developed in chapter five with the title "Not Going To Hell in a Handbasket: Existentialism and a World without Morality."

In the course of making his case against moral realism, Irwin offers this illuminating comparison of moral realism and theism:

Ironically, many people who reject the existence of God because they see God as an unnecessary hypothesis continue to cling to the unnecessary hypothesis of objective morality. Of course there could be objective moral facts; it is impossible to disprove their existence. But that is just like the case of God, whose non-existence is unprovable. Defenders of objective morality commonly appeal to their moral experience as justification for their belief. But many of these same people would find laughable the appeal to religious experience as justification for belief in God. If feelings and vague experiences won't work 
to prove God's existence, then they cannot prove the existence of moral facts either. (Irwin 2015, 106)

I shall now seek to overturn Irwin's case for moral anti-realism.

\section{Assessing Irwin's reasoning}

First, consider the philosophical limitations of claims about what evolutionary adaption can explain. Note how evolutionary adaptability has a highly limited role in accounting for our justified beliefs in many areas such as logic. Take the claim: "we evolved to have inclinations to punish, to have feelings of guilt, and to have beliefs in right and wrong” (Irwin 2015, 106) and compare it with the claim that we evolved to have inclinations to practice logical, mathematical, and scientific reasoning, which involves the recognition of objectively sound entailment relations. In the second case, it would be preposterous to hold that we can explain (let alone understand) necessary, logical relations on the grounds of their role in any evolutionary process. To grasp such truths as 2 plus 2 is 4 , there is no greatest possible number, the successor of any number is a number, no two numbers have the same successor or more general truths such as everything that has volume, has shape, and so on, may enable one to survive and reproduce but the content and truth of these propositions does not involve anything to do with survival and reproduction. The principles of logic and mathematics concern entailments between properties (and sets) that we grasp are necessary in themselves and necessary presuppositions for there to be any thought whatsoever. To entertain any thought (label it X), one must assume the law of identity (X is $\mathrm{X}$ or everything is itself, for example snow is snow) and the law of non-contradiction ( $\mathrm{X}$ is not not-X or nothing can be both $X$ and not $X$ at the same time and in the same respect). Cases of when it might appear that the law of identity is violated (e.g. "boys are not always boys") are due to linguistic vagueness or equivocation (e.g. the first use of the term "boys" means "young males" while the second usage means "acting the way young males are typically thought to act, for example, immaturely.") The necessary truth that $2+2=4$ is based on the inviolable law of identity 
which is grasped independent of any sensory experience $1+1+1+1=1+1+1+1$. So, observing an amoeba splitting into two does not give any reason of any kind to believe $1=2$ because numerical truths about multiplication are different from truths about how organisms reproduce (or, as it were, how their material multiplying as in the sense of growing, takes place). If you want to offer an evolutionary account of how animals evolved to do mathematics one may well appeal to how proper counting (for example) is more adaptive than being terrible at quantified reasoning, but such mathematical skills are adaptive because they reflect necessary entailment relations, they do not reflect necessary entailment relations because they are adaptive. As John Hospers observes:

If the universe consisted of an unending series of evanescent events like lightning flashes, "A is A" would still old true. It tells you nothing about the particular character of the world: it holds true for "all possible worlds." (Hospers 1967, 209)

Going back to Irwin's succinct description of our evolutionary past in which we humans came to live in groups and adapt to "group norms" of reciprocity (helping those who help you), human beings would not have been capable of doing this without presupposing elementary logic such as if there is a group, there is a group, if a person is helped, a person is helped, if you have a child, it is not the case that you have not had a child, and so on. It also seems unimaginable that persons would bond together to engage in "reciprocity, helping those who help you and harming those who harm you" without having concepts of help and harm and reciprocity. Of course there is subjective variance historically in many cases of what counts as harm (in certain cultures females are not thought of as harmed when they are treated as de facto slaves of males), but it is very hard not to recognize certain, core objective harms throughout human history such as blinding one's children, cutting off their limbs, removing one of their ears, etc. Even in cases of child sacrifice (when there might be some belief in a child surviving its sacrifice on the other side of death), the dismemberment and mutilation of the child in this life is unintelligible unless it is understood 
as a sacrifice (involving the harming of a child in this life for some greater good perhaps, but still a harm). Irwin's discussion of the case of torturing children is odd. He claims that feeling the torture of children for fun to be abhorrent "does not make it true that the action is morally wrong." The prior, more important point is whether the child's feelings (its painful, extreme suffering) isn't precisely what makes the act of torture a case of harming the child. The torturer (almost by definition) is doing something that is objectively bad for the child. It seems wild to not think that ripping off a child's arm would not be objectively bad for the child, a genuine harm, if there ever was one. The point at issue may be refined in the context of various schools of moral realism, but it is especially congenial to the common sense, Aritstotelian-Thomist understanding that human beings have a well-being (eudaimonia) that more than adequately affirms the thesis that ripping off the child's arm is objectively bad for the child. All this, it should be added, can be secured without appeal to some alien, mystical faculty.

So, even in Irwin's snapshot of our evolutionary past, it seems difficult to fill out hi position without making explicit when persons objectively benefit or harm each other. Unless parties to the agreed upon mutual restraints realized that ripping up their own or their children's arms was bad for them, why would they agree to mutual restraint to provide mutual protection. Indeed, it would be hard to understand whether humans even could survive and evolve if they constantly harmed offspring (ripping off limbs and so on). Insofar as reproduction, the nurturing of children, is part of Irwin's portrait of early group communities, there would have to be stable practices enabling them to recognize when harming offspring would prevent them reproducing and, presumably, there are objective facts about this matter of when a harm would be so severe as to prevent continuation of a community [cf. Thomas Aquinas's Summa Theologica, Prima Secundae Qu. 94, art. 2].

I suggest that we do have an enduring, stable belief that for any individual mammal (a human or dog or a sheep) to harm it is bad for the organism unless this is for some good or the prevention of some greater harm for the individual or the community. Harming an individual mammal 
might be deemed an overall good for all kinds of reasons (killing a sheep in order to eat its meat), but that does not mean that the harm itself is good for the individual. None of this seems at all mysterious. The fact that if we had had a different biological evolution, our judgments about harms and benefits, goods and ills, would differ does not compromise the objectivity of the judgments. With some reluctance, Irwin's case of the dog liking or even eating its faeces is due to all sorts of reasons having to do with the replenishing of enzymes, a sign that it is not getting enough nutrients, and so on. If we had a radically different biology or anatomy, our understanding of harms and benefits would shift. Imagine our bodies evolved to become resistant to heat and that we developed different lungs that enabled us to breathe under water. Under those circumstances we might be less worried about burns and drowning. That would not do anything to call into question the objective harm involved in shooting a person's leg with a gun or hanging them by a rope, etc, etc.

Irwin writes, however, as if objective moral facts are different from ordinary, common sense facts about harming, benefiting, and reciprocating. After all, he likens moral facts to ghosts, angels, souls, and gods, not to cuts and bruises, starving to death innocent persons versus rescuing innocent persons from famine, and so on. But whatever our view of ghosts, et al., why not recognize that objective moral facts are akin to the norms we recognize in logic, mathematics, and the norms that govern our grasp and inquiry into the nature of the world (whether this is a matter of common sense or advanced science)?

In logic, common sense, and science, we routinely appeal to rules or norms of evidence. Human history may well be viewed as an evolution toward better and better understandings of evidential relations, relying less on oracles, auguries, and dreams to divine the future, and relying more and more on disciplined observations, experiments, the development of theories of explanation from forensics to modern science, and beyond. Irwin writes as if the idea that our ethical judgments track the truth of objective moral relations or facts is "scientifically unacceptable." But it is hard to conceive of scientific practice without conceiving of a practice that 
is saturated with (ostensibly) objective truths about what is acceptable and unacceptable, right and wrong, valid or invalid reasoning. You will not have a scientific community unless there is a commitment to being trust-worthy in reporting observations. Nor will you have science without grasping the objectivity of evidential relations: knowing that one set of observations justifies one hypothesis over another. We can generate any number of scientific cases involving atomic theory, but let's instead take note of our recognition of objective evidential norms (truths about what and how some propositions are made evident by some, and not other observations) in very mundane circumstances. Your having the experiences and ideas you are currently having, is very good reason to believe you are reading this article. Hopefully, your reading this sentence is good evidence that it was not produced by a computer that was programmed to create completely random words without any reference to semantics or syntax. Our reasoning is governed by the apprehension of normative epistemic relations in which we readily distinguish between sound reasoning and fallacies, jokes or nonsense, e.g. Newton went to Cambridge, there is a black swan in Australia, therefor you love Veronica.

So, while some moral realists will portray objective moral facts in terms of an extraordinary metaphysic, they may be (and should be, in my view) seen as no stranger than our ordinary and scientific reliance on normative relations. Erik Wielenberg offers the following exultant portrait of moral realism. Brute, ethical facts "come from nowhere, and nothing external to themselves grounds their existence; rather, they are fundamental features of the universe that ground other truths" (Wielenberg 2009, 26). This portrait makes it seem as if brute facts come swooping in upon us, externally strutting about the natural world, rather than objective moral facts being no stranger than the objective fact that when you subject an innocent, involuntary human person to deep skin laceration, you are harming her (this is an objective fact of the matter and its harm is fully experienceable by the victim). No appeal to simplicity or parsimony can (in my view) defeat the evident, objective harm we can recognize when an innocent person is subject to such harm. 
What about Irwin's idea that, while moral realism may be defended if we adopt epistemological conservatism, such a position should be rejected? Recall that Irwin writes: "There are any number of beliefs that are naturally very strong and that turn out to be false: the earth is flat, the sun orbits the earth, and so forth.” There are sophisticated philosophical arguments about the problem of encountering persons and cultures that we believe hold massive numbers of false beliefs, but I appeal instead to a common sense point that surely those who have adopted moral realism over the centuries are not those who can reasonably be imagined to have vastly false core beliefs. For example, it is widely been exposed as a fallacy that great numbers of people in the past believed that the earth is flat. While some in the Ancient Greco-Roman believed the sun was the centre of our solar system, this took more time to become secure, but no one has shown it to be false that, from the standpoint of our visual, earthly perspective we see the sun rising and setting, etc. My point is that it is a stretch (to put it mildly) to go from observing that in the past we had mistaken views of our solar system and anatomy (Aristotle, for example, thought that the purpose of the brain was to cool our blood), that we did not in the past or today have a grasp (in both extreme and mundane cases) of objective truths about when something is good or bad for persons (depriving a human person of water will be very bad for them; feeding human persons nourishing food is good for them).

More is involved in ethical moral realism than we have covered. We have not entered into questions about whether some form of natural law and virtue theory should be preferred to utilitarianism or Kantianism. My focus has, instead, been on rebutting Irwin's case against moral realism. But I now turn to Irwin's suggested link between moral realism and theism.

\section{Arguments for moral realism and theism}

Irwin makes an interesting claim about whether a moral realist's reliance on the evidential significance of moral experience would naturally lead to entertaining the evidential experience of religious experience. I remind readers of this claim: 
Defenders of objective morality commonly appeal to their moral experience as justification for their belief. But many of these same people would find laughable the appeal to religious experience as justification for belief in God. If feelings and vague experiences won't work to prove God's existence, then they cannot prove the existence of moral facts either. (Irwin 2015, 106)

As should be apparent, I do not think our moral feelings and experience are vague. I think we have a robust experiential realization of when there are objective goods and ills for human beings (and some animals). As I have argued elsewhere in this journal (Taliaferro 2015), I propose that philosophers today lack a clear, stable concept of the world as a mind-independent, secular realm in which the mental and the divine is altogether alien or experientially opaque. I suggest in closing that both our moral experiences and our religious experiences of God have a perceptual structure so that both of them function as ostensible apprehensions of that which is real (disclosing the reality of ethical truths and the reality of the divine). Once one appreciates that the effort is futile to restrict scientific and objective inquiry to value-free empirical methodology, the door is open to recognizing the important evidential value of religious experience (Kwan 2011).

\section{References}

Irwin, William. 2015. The Free Market Existentialist. Oxford: Wiley Blackwell.

Hospers, John. 1967. An Introduction to Philosophical Analysis. Englewood New Jersey: Prentice-Hall.

Kwan, Kai-man. 2011. The Rainbow of Experience, Critical Trust, and God. New York: Continuum.

Ruse, Michael. 1986. Taking Darwin Seriously. Oxford: Blackwell.

Ruse, Michael and Edward O. Wilson. 1994. "Moral Philosophy as Applied Science.” In Conceptual Issues in Evolutionary Biology, edited by Elliott Sober. $2^{\text {nd }}$ edition. Cambridge: Cambridge University Press.

Taliaferro, Charles. 2015. “The Ordinary is Extraordinary: the Wonder of the Mundane Physical World.” Scientia et Fides 3 (2): 107-116. DOI: http://dx.doi.org/10.12775/ SetF.2015.021

Wielenberg, Erik. 2009. “In Defense of Non-Natural, Non-Theistic Moral Realism.” Faith and Philosophy 26: 23-41. DOI:10.5840/faithphil20092612 